\title{
Transient tractional retinal detachment in an eye with retinitis pigmentosa
}

This article was published in the following Dove Press journal:

Clinical Ophthalmology

23 September 2010

Number of times this article has been viewed

\author{
Shuichiro Hirahara \\ Yoshio Hirano \\ Tsutomu Yasukawa \\ Yuichiro Ogura \\ Department of Ophthalmology and \\ Visual Science, Nagoya City University \\ Graduate School of Medical Sciences, \\ Nagoya, Japan
}

\begin{abstract}
We present a case of retinitis pigmentosa with vitreoretinal traction-associated retinal detachment. The retinal detachment was detected in the nasal periphery. No retinal breaks and no active vascular leakage were observed by fundus scopy and fluorescein angiography, respectively. However, 8 months later, the tractional retinal detachment was spontaneously resolved with posterior vitreous detachment.
\end{abstract}

Keywords: retinitis pigmentosa, vitreoretinal traction, retinal detachment

\section{Introduction}

Retinitis pigmentosa (RP) was defined as a group of hereditary disorders that diffusely involve photoreceptor and pigment epithelial function characterized by progressive visual field loss and abnormal electroretinogram. RP also has changes at vitreoretinal interface, such as vitreoretinal traction and preretinal membrane, which causes macular disorders such as cystoids macular edema and macular hole. We report a case of vitreoretinal traction syndrome associated with RP, which spontaneously resolved after posterior vitreous detachment (PVD).

\section{Case report}

A 81-year-old woman presented with bilateral loss of peripheral vision and defective dark adaptation 15 years before. The best-corrected visual acuity was 20/28 and 20/28 in the right and left eyes, respectively. Slit-lamp examination showed bilateral retinal arteriolar narrowing and intraretinal pigment deposition (bone spicule pigmentation) in both eyes (Figure 1A). The visual fields of the patient were markedly constricted to the central $10^{\circ}$ in both eyes (Figure 2). On June 2, 2006, retinal detachment was detected in the nasal periphery in the right eye (Figures 1B and 1C). At that time, PVD was confirmed with Weiss ring (Figure 3). Fluorescein angiography showed a hyperfluorescence due to atrophy of retinal pigment epithelium but no active leakage in the detached area (Figure 1C). Fundus examination revealed no retinal breaks. Therefore, we diagnosed tractional retinal detachment associated with vitreoretinal traction. The detached area was within the area where the visual field was lost, and we observed a clinical course of this eye without any treatment. Retinal detachment was kept localized and not extended. Five months later, PVD further progressed beyond the arcade area, accompanying retinal hemorrhage around the detached retina. Thereafter, the tractional retinal detachment and retinal hemorrhage were gradually resolved. Eight months later, the retina was completely reattached.
Department of Ophthalmology and Visual Science, Nagoya City University Graduate School of Medical Sciences, I-Kawasumi, Mizuho-cho, Mizuho-ku, Nagoya 467-860I, Japan

Tel $+8 \mid-52-853-825$ I

Fax +8I-52-84I-9490

Email yossyeye@med.nagoya-cu.ac.jp 


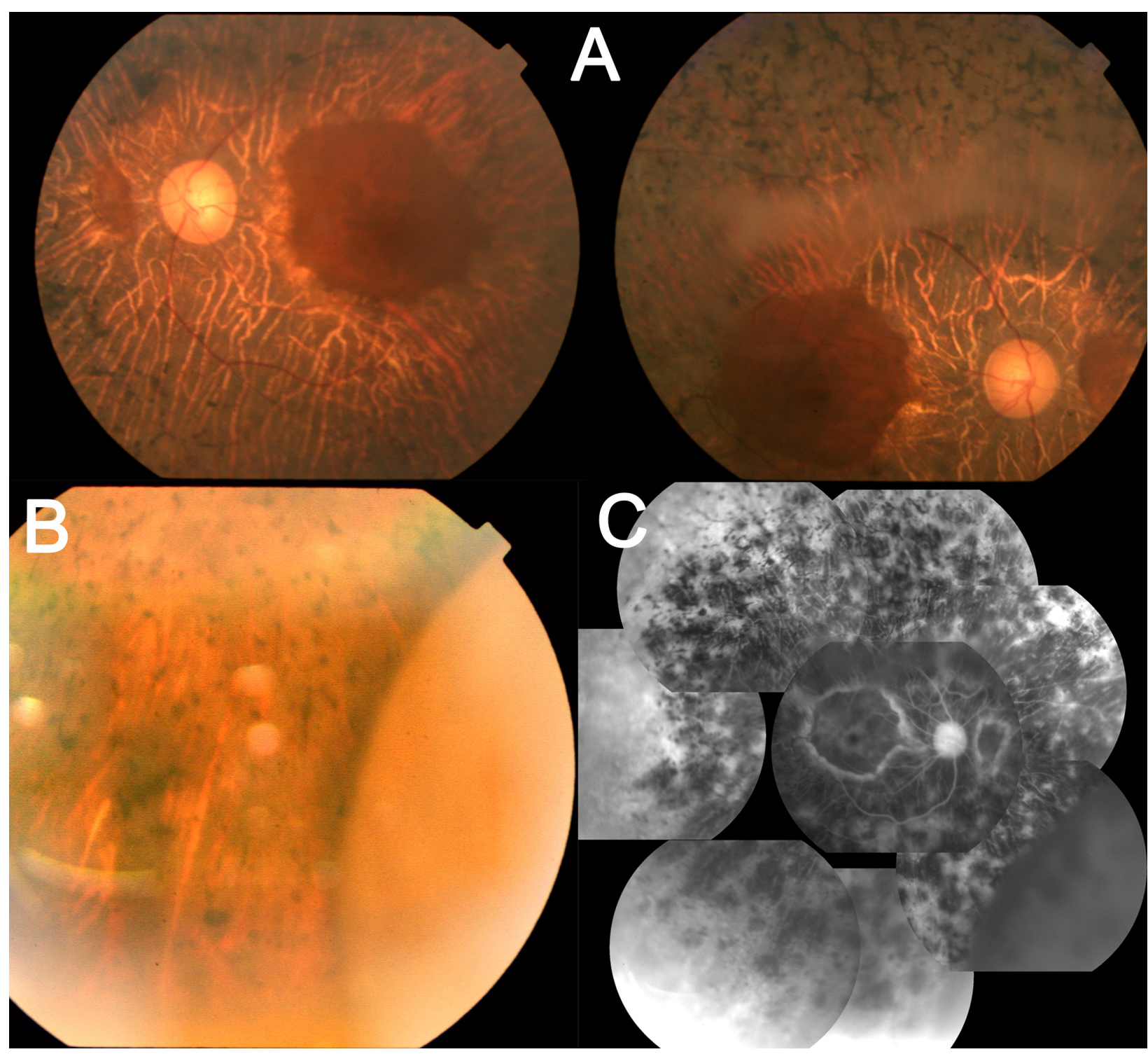

Figure I Photographs of a $8 \mathrm{I}$-year-old woman with retinitis pigmentosa. A) Fundus photographs show bilateral retinal arteriolar narrowing and intraretinal pigment deposition (bone spicule pigmentation) in both eyes, left: left eye, right: right eye. B) A fundus photograph of the right eye using a slit-lamp examination shows a detached retina in the nasal periphery. C) Fluorescein angiography images of the right eye show a hyperfluorescence due to atrophy of retinal pigment epithelium and hypofluorescence in the detached area.

\section{Discussion}

In this case, an eye with RP was complicated with tractional retinal detachment, possibly associated with increased vitreoretinal traction secondary to the incidence of PVD. The retinal detachment was limited within the area where the visual field was lost and was not progressive. Therefore, we observed a clinical course of the patient without any surgical treatment. Eight months later, spontaneous resolution of tractional retinal detachment resulted from progression of PVD, which was suggested by transiently increased traction-related retinal hemorrhage. Eyes with RP may have abnormal liquefaction of vitreous and altered distribution of vitreoretinal adhesion. The incidence of PVD in the posterior pole might result in the focal remarkable traction in the peripheral retina and tractional retinal detachment. Eight months later, the retinal detachment was resolved because local vitreoretinal traction was weakened with extention of PVD beyond the arcade vessels.

RP has vitreomacular traction-related pathologic events involving vitreomacular traction syndrome, cystoids macular edema, and macular hole. ${ }^{1-3}$ Such changes in this patient with $\mathrm{RP}$ might result in a tractional retinal detachment. Rani et $\mathrm{al}^{4}$ reported that a 50-year-old man underwent a tractional retinal detachment involving the posterior pole with a taut posterior hyaloids surface. In this study, vitrectomy was not performed because the patient opted for no surgical intervention in 


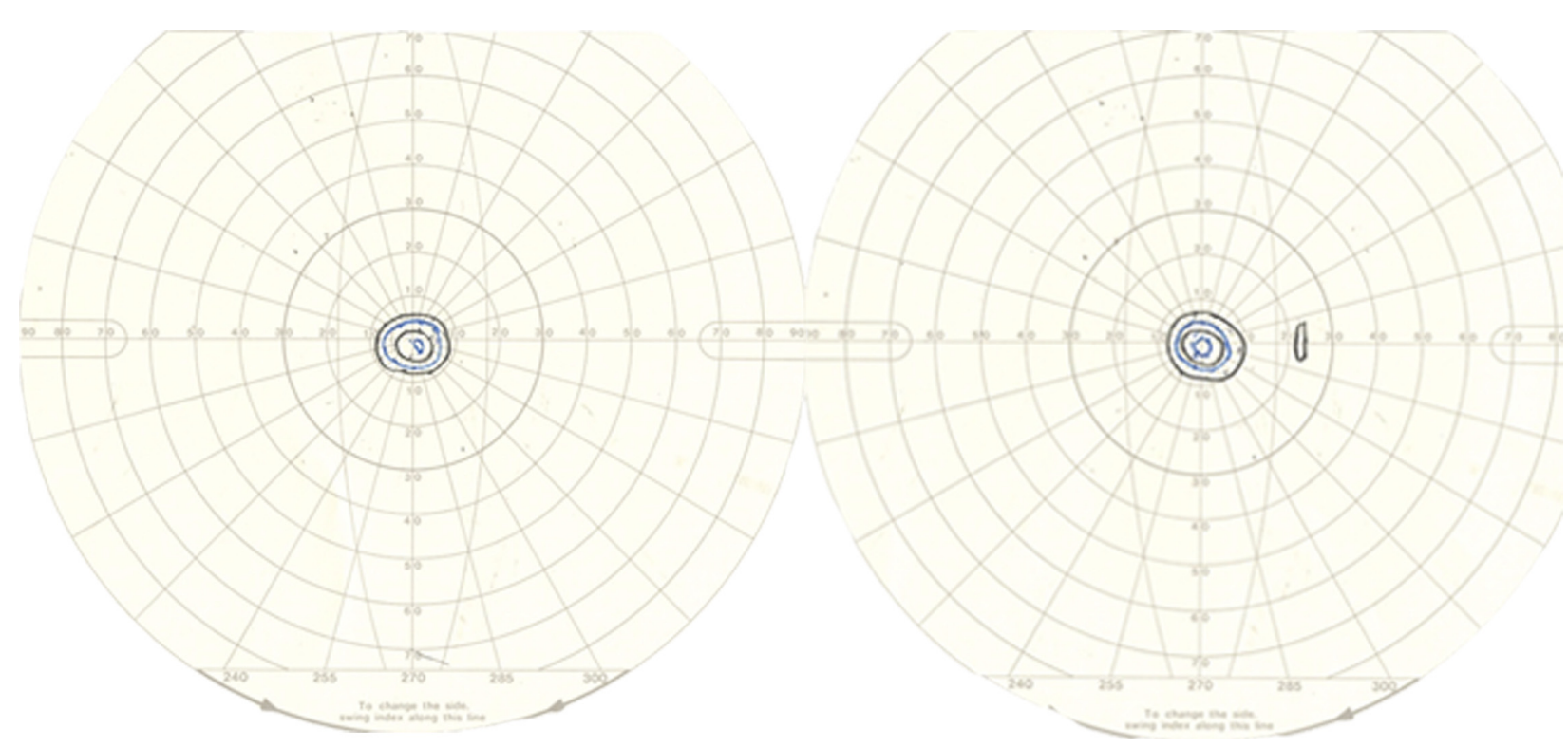

Figure 2 Visual fields of left eye (left) and right eye (right) of a patient with retinitis pigmentosa using a Goldmann perimeter were markedly constricted to the central $10^{\circ}$ diameter.

view of poor prognosis. On the other hand, it was reported that vitrectomy was effective for vitreous opacity, ${ }^{5}$ cystoid macular edema, ${ }^{6}$ exudative retinal detachment, ${ }^{7}$ and macular holes $^{8}$ in RP. However, regarding the indication to perform a vitrectomy, the balance of the expected gain in visual function and usual risks of vitrectomy and RP-related risks, such as phototoxicity worsening of visual field loss, and cystoid macular edema. It might be a choice that a patient with tractional retinal detachment in RP is observed without surgical treatment, if the detached area is not progressive.

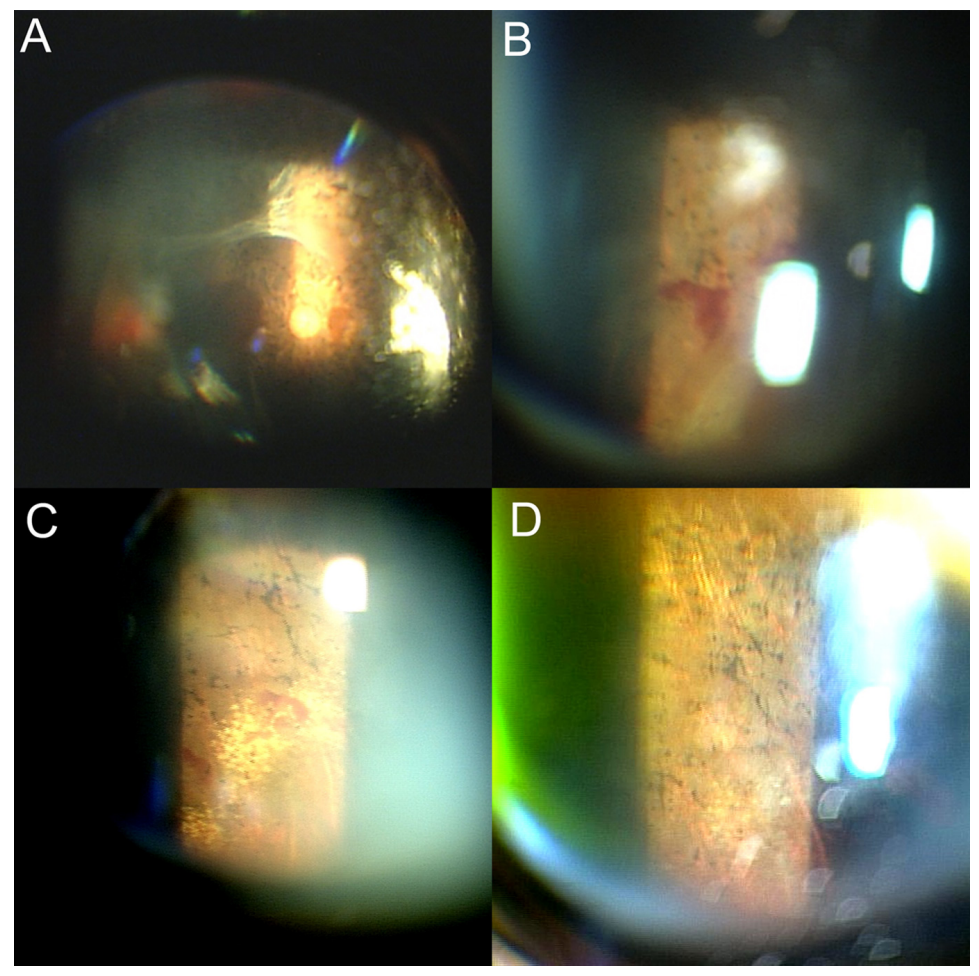

Figure 3 The right eye of the same patient. A) and B) A fundus photograph using a slit-lamp examination of 5 months later shows that the posterior vitreous detachment further progressed beyond the arcade area $\mathbf{A}$ ), accompanying retinal hemorrhage around the detached retina $\mathbf{B}$ ). C) A fundus photograph using a slit-lamp examination of 8 months later shows that the retina is reattached, and hard exudates are observed in the nasal periphery. D) A fundus photograph using a slit-lamp examination of I 2 months later shows that those hard exudates are resolved. 


\section{Disclosure}

The authors report no conflicts of interest in this work.

\section{References}

1. Fishman GA, Fishman M, Maggiano J. Macular lesions associated with retinitis pigmentosa. Arch Ophthalmol. 1977;95:798-803.

2. Wise GN. Clinical features of idiopathic preretinal macular fibrosis. Schoenberg Lecture. Am J Ophthalmol. 1975;79:349-357.

3. Demir MN, Unl N, Yalniz Z, Acar MA, Ornek F. A case of retinal detachment in retinitis pigmentosa. Eur J Ophthalmol. 2007;17: 677-679.

4. Rani A, Pal N, Azad RV, Sharma YR, Chandra P, Vikram Singh D. Tractional retinal detachment in usher syndrome type II. Clin Experiment Ophthalmol. 2005;33:436-437.
5. Hong PH, Han DP, Burke JM, Wirostko WJ. Vitrectomy for large vitreous opacity in retinitis pigmentosa. Am J Ophthalmol. 2001;131: 133-134.

6. Garcia-Arumi J, Martinez V, Sararols L, Corcostegui B. Vitreoretinal surgery for cystoids macular edema associated with retinitis pigmentosa. Ophthalmology. 2003;110:1164-1169.

7. Lee SY, Yoon YH. Pars plana vitrectomy for exudative retinal detachment in coats-type retinitis pigmentosa. Retina. 2004;24:450-452.

8. Jin ZB, Gan DK, Xu GZ, Nao-IN. Macular hole formation in patients with retinitis pigmentosa and prognosis of pars plana vitrectomy. Retina. 2008;28:610-614.
Clinical Ophthalmology

\section{Publish your work in this journal}

Clinical Ophthalmology is an international, peer-reviewed journal covering all subspecialties within ophthalmology. Key topics include: Optometry; Visual science; Pharmacology and drug therapy in eye diseases; Basic Sciences; Primary and Secondary eye care; Patient Safety and Quality of Care Improvements. This journal is indexed on

\section{Dovepress}

PubMed Central and CAS, and is the official journal of The Society of Clinical Ophthalmology (SCO). The manuscript management system is completely online and includes a very quick and fair peer-review system, which is all easy to use. Visit http://www.dovepress.com/ testimonials.php to read real quotes from published authors. 